\title{
A Dimmable LED Driver with Fault Tolerance for Automotive Lighting
}

\author{
Shian-Nan Lin ${ }^{1}$, Tung-Yen Lee ${ }^{2}$, Zheng-Yan He ${ }^{1}$, Yao-Ching Hsieh ${ }^{1}$, Yong-Nong Chang ${ }^{3}$, Chin-Sien Moo ${ }^{1}$ \\ ${ }^{1}$ Department of Electrical Engineering National Sun Yat-Sen University \\ 70 Lienhai Rd., Kaohsiung 80424, Taiwan, R.O.C. \\ D053010004@student.nsysu.edu.tw; ian0975288510@gmail.com.tw; ychsieh@mail.ee.nsysu.edu.tw; \\ mooxx@mail.ee.nsysu.edu.tw \\ ${ }^{2}$ Photovoltaic Inverter BU, Delta Electronics, Inc. \\ 39 Section 2, Huandong Road, Shanhua District, Tainan 74144, Taiwan, R.O.C. \\ magic.kinder25@yahoo.com.tw \\ ${ }^{3}$ Department of Electrical Engineering National Formosa University \\ No.64, Wunhua Rd., Huwei Township, Yunlin County 632, Taiwan, R.O.C. \\ ynchang@nfu.edu.tw
}

\begin{abstract}
This paper proposes a driver circuit with dimming feature and fault tolerance mechanism for the automotive lamp formed by several light-emitting diodes (LEDs) in series. With capability of step-up/down voltage conversion, the driver circuit can be operated both in wide ranges at input and output voltages by exchanging the associated active power switches and adjusting the corresponding duty-ratios. A laboratory circuit is designed for an automotive lamp with five LEDs in series, which is powered by a battery set with a voltage ranged from $8 \mathrm{~V}$ to $13.5 \mathrm{~V}$. Experimental results have demonstrated that the LED driver can be smoothly swapped between the step-up mode and step-down mode when the fault tolerance has been initiated. As compared to the conventionally used dc-to-dc converters, the proposed LED driver has advantages of high circuit efficiency and low lamp current ripple.
\end{abstract}

Keywords: Light-emitting diode (LED), Automotive lamp, Step-up/down converter, Fault tolerance.

\section{Introduction}

Nowadays, light-emitting diodes (LEDs) are widely used in many lighting and display applications with the advantages of small volume, fast response, long life, wide dimmable range, and most importantly high luminous efficiency [1-3]. Among which, the high-brightness LEDs have been used for automotive lighting to replace traditionally used halogen lamps and high intensity discharge lamps. In the application of automotive lighting, the power conversion circuit of the LED lamp driver has to be of high efficiency since the space for installation and heat dissipation in an automobile is always small. In addition, the lifetime and luminous efficacy of LEDs are critically affected by the ambient temperature [4-7].

In general, an automotive lamp is formed by a number of LEDs to meet the required luminous intensity. These LEDs are connected in series to have an identical current and thus the generated luminous flux. A protection circuit is included to prevent the malfunction in the case that a failing happens to some LEDs in the string. In practice, the automotive LED lightings are supplied from a battery set with a dc voltage which may vary in a wide range depending on its state-of-charge. To cope with the variations of the battery voltage and dimming feature of the LED lamp, a dc-to-dc converter is necessary to step up or down to regulate the LED current [8-16].

The dc-to-dc converter introduces inevitably a ripple on the LED lamp current, which can have negative effects on the brightness and luminous efficiency. To reduce the ripple on the LED current, conventionally, a large electrolytic capacitor is added at the output of the driver circuit. Nevertheless, the lifetime of this electrolytic capacitor can be the critical component to the LED lamp [17-20].

To improve the reliability and the efficiency of the automotive lighting, a driver circuit is designed for a string with 5 LEDs. The LED driver circuit can be operated in either the step-up mode or the step-down mode for different number of working LEDs at a required lamp current for dimming function and fault tolerance. In addition, the ripple on the LED current can be mitigated without the need of electrolytic capacitors.

\section{Circuit Configuration}

The driver circuit of the proposed LED lamp is shown in Fig. 1. It consists of substantially two power converters to step 
up or down the output voltage. The power conversion circuit of the driver is supplied from a battery set, which can be regarded as a variable dc voltage source, $v_{\text {in }}$, since the battery voltage may vary with the battery status and the discharged current. The output terminal voltage, $v_{o}$, is applied on the LED lamp which is composed of several LEDs connected in series.

The step-down voltage converter is formed by two back-to-back active power switches, $S_{2}$, and $S_{3}$, a coupled inductor with two windings, and a filter capacitor, $C_{r}$. The inductances of two windings on the primary and secondary sides are $L_{p}$ and $L_{s}$, respectively. A freewheeling diode, $\mathrm{D}_{1}$, is connected in series with the secondary winding of the coupled inductor to conduct the freewheeling current to the LED string. This is helpful for reducing the current ripple during the step-down voltage conversion mode.

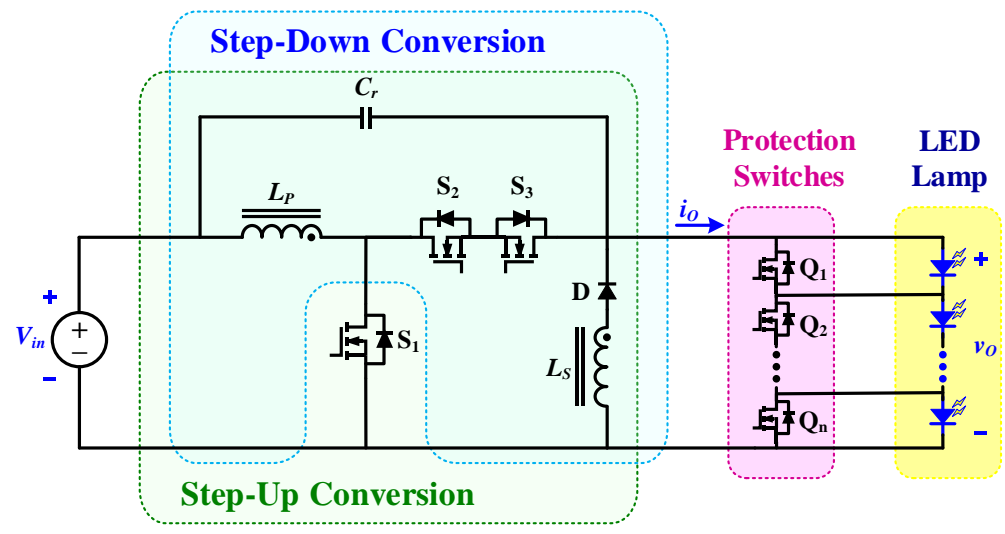

Fig. 2: Proposed LED driver circuit.

An active power switch, $S_{1}$, is employed for the step-up voltage converter to regulate the LED power. The step-up converter uses only the primary side of the coupled inductor. The commonly used back-to-back active power switches play the role of the synchronous rectification. The voltage on the LED string is stepped up by adjusting the duty-ratio of $\mathrm{S}_{1}$. Both the step-up and step-down converters are intendedly operated at the discontinuous conduction mode (DCM) so that the active power switches can be switched off at zero-current, leading to a reduction of the switching losses.

Each LED in the lamp is attached by an active switch for protection. In the case that an abnormal voltage has been detected on the LED, the associated protection switch is activated to provide a bypass for the LED string.

\section{Circuit Operation}

\subsection{Step-down voltage conversion}

The operation of the step-down voltage converter in a high frequency cycle can be illustrated by four stages as shown in Fig. 3 with the help of the theoretical waveforms on the key components depicted in Fig.4.

At Stage I, the battery set delivers a current to the LED lamp, and at the same time charges the filter capacitor $C_{r}$ and the primary side of the coupled inductor. This stage ends when the inductor current $i_{p}$ is equal to the LED current $i_{o}$. The primary side inductor current $i_{p}$ continues to increase up at Stage II, since it is charged by $C_{r}$. In other words, $C_{r}$ is discharged by $i_{p}$ resulting in a declining voltage.

Stage III begins when the two back-to-back active power switches $S_{2}$ and $S_{3}$ are switched off. At this stage, the energy stored in the coupled inductor is released by the secondary side winding. The peak of the secondary side current, $i_{s}$ is designed to be always less than the LED current $i_{o}$. The filter capacitor $C_{r}$ is charged by the current difference between $i_{o}$ and $i_{s}$, meaning that the LED current is supplied simultaneously by the battery and the secondary side inductor. As a result, $i_{s}$ declines and the voltage on $C_{r}$ is charged up.

Stage IV begins when the secondary side inductor $i_{s}$ declines to zero. At this stage, the battery supplies the LED current and simultaneously charges the filter capacitor $C_{r}$.

\subsection{Step-up voltage conversion}

The driver circuit is operated with the step-up mode when the battery voltage $v_{\text {in }}$ is lower than the output voltage $v_{o}$ on the LED lamp. The LED voltage and current can be regulated by controlling the duty-ratio of the active power switch $\mathrm{S}_{1}$. The two back-to-back power switches carry the freewheeling current from the primary side inductor. The step-up voltage conversion can be described by four stages as shown in Fig.5. The theoretical waveforms on the key components 
are shown in Fig.6.

At Stage I, the primary side inductor is charged by the battery set by switching on the active power switch $S_{1}$. The LED current is supplied from the battery in series with the filter capacitor $C_{r}$. The primary-side inductor current, $i_{p}$ increases linearly and reaches its peak when $S_{1}$ is turned off.

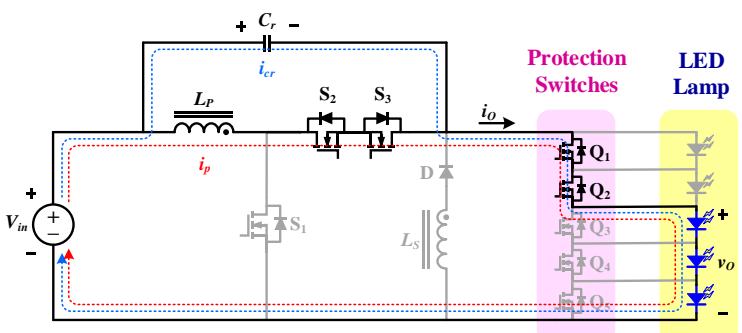

(a) Stage I

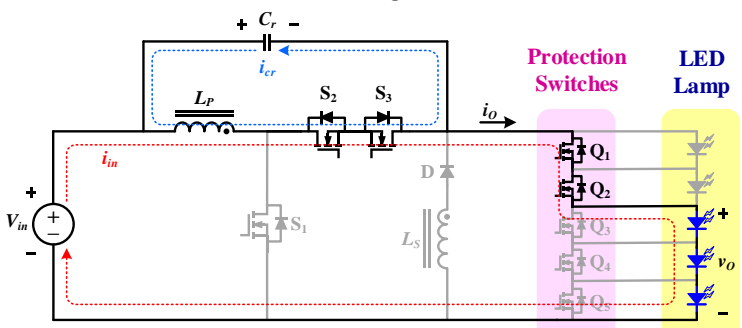

(b) Stage II

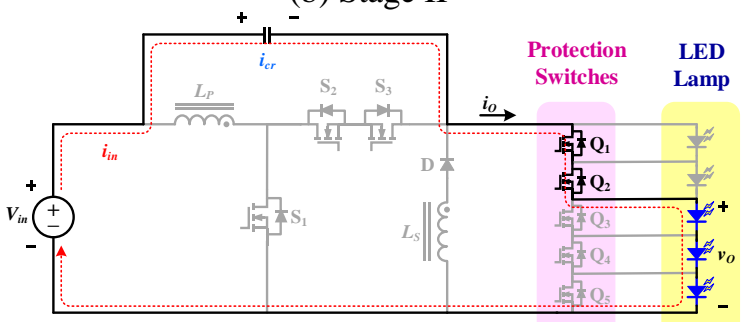

(c) Stage III

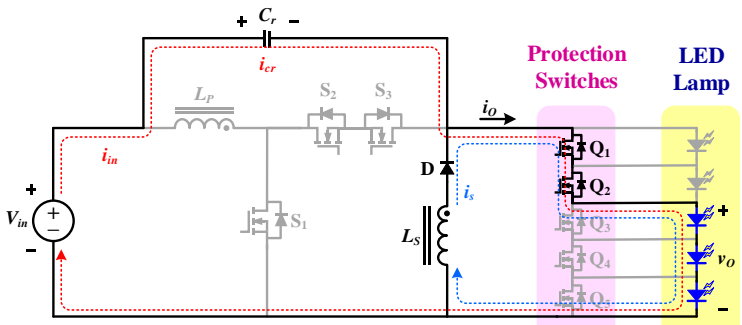

(d) Stage IV

Fig. 3: Operation stages of step-down voltage conversion.

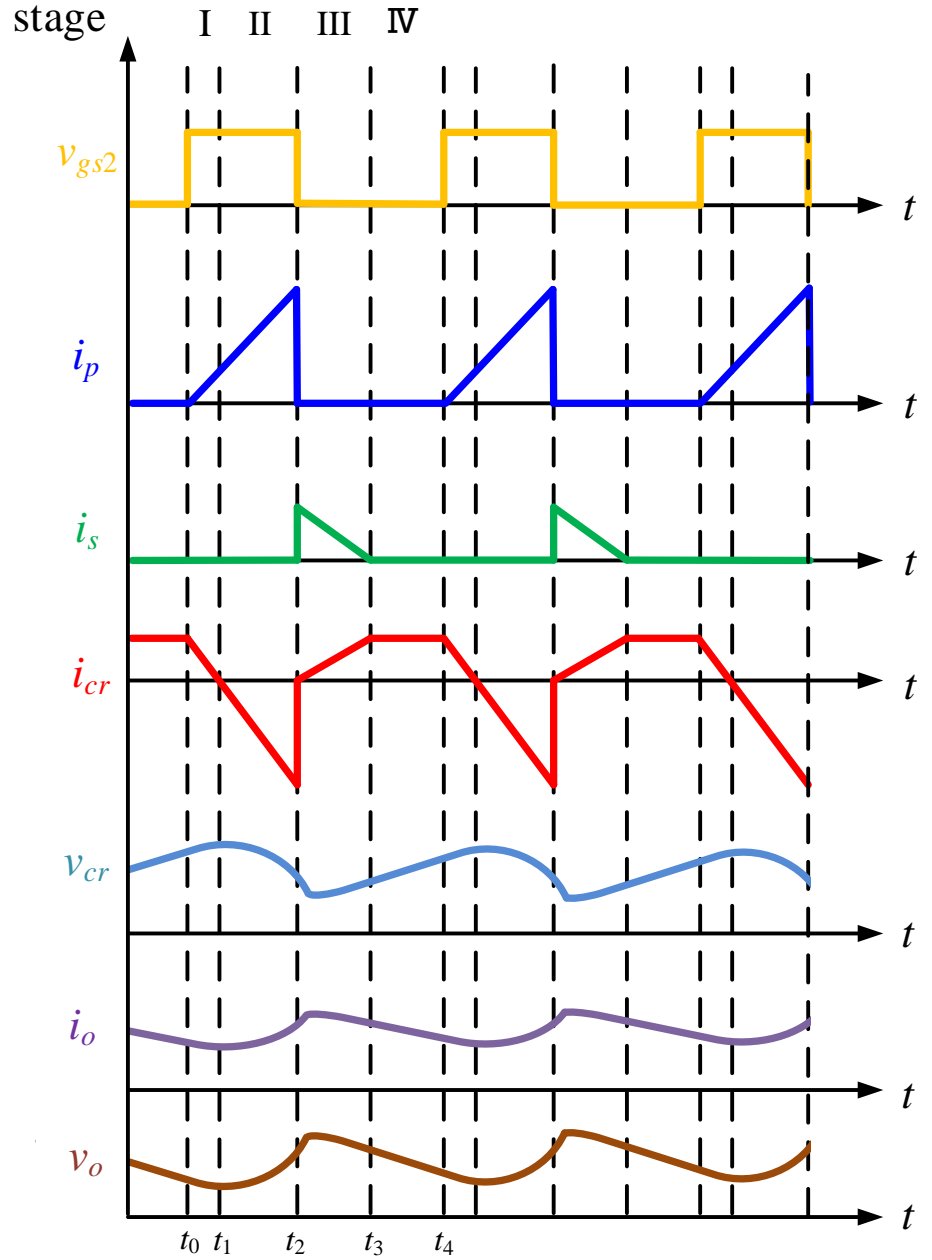

Fig. 4: Theoretical waveforms of step-down mode.

Stage II begins when $S_{1}$ is switched off. One of the two back-to-back power switches, $S_{2}$, remains always on to carry the freewheeling current from the primary side inductor. The other one, $S_{3}$, is switched on after a short dead time to perform the function of synchronous rectification. At the beginning of the freewheeling period, the inductor current $i_{p}$ is larger than the output current $i_{o}$. The inductor current provides the LED current and at the same time an excessive current flows to the filter capacitor $C_{r}$, causing an increase in the voltage.

At Stage III, the inductor current $i_{p}$ continues to decline and then becomes smaller than the output current $i_{o}$. During this stage, the LED current is supplied from the battery and the filter capacitor $C_{r}$.

Stage IV starts when $i_{p}$ declines to zero. At this stage, the active power switch $\mathrm{S}_{1}$ and $\mathrm{S}_{3}$ remain off. The LED current is supplied by the battery set. At the same time, the filter capacitor $C_{r}$ is discharged until the active power switch $\mathrm{S}_{1}$ is switched on again for the next cycle. 


\section{Experimental Results}

A driver circuit is designed for an automotive LED lamp, which is formed by five LEDs in series. Table I lists the circuit parameters and specifications for this design example. Each LED is rated at a voltage of $3.3 \mathrm{~V}$ and a current of 1 A, respectively. The driver is capable of driving from one to five LEDs with fault tolerance mechanism. In other words, the LED lamp voltage can vary from $3.3 \mathrm{~V}$ to $16.5 \mathrm{~V}$. The switching frequency of the power conversion circuit is designated at $100 \mathrm{kHz}$. With adequately designed circuit parameters, the power conversion circuit is operated at the DCM. The LED lamp current can be dimmed to $0.1 \mathrm{~A}$ from a rated current of $1.0 \mathrm{~A}$.

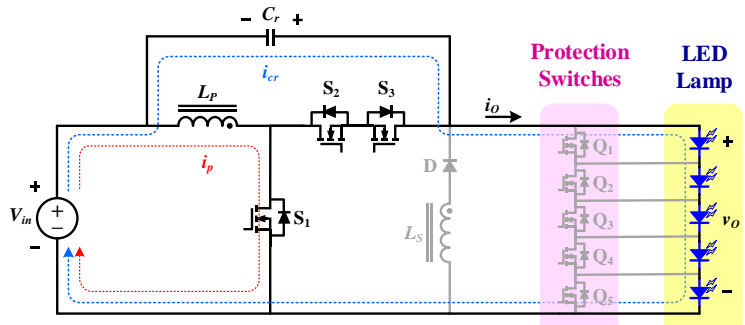

(a) Stage I

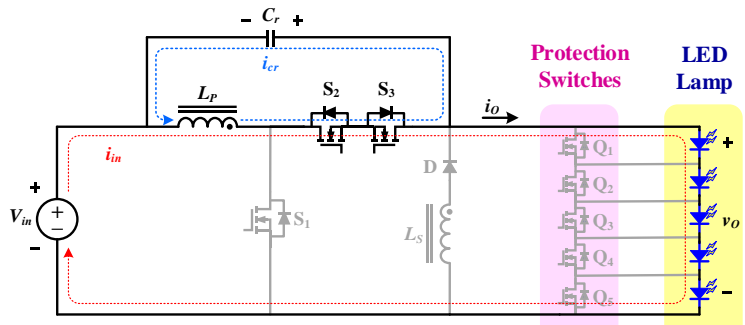

(a) Stage II

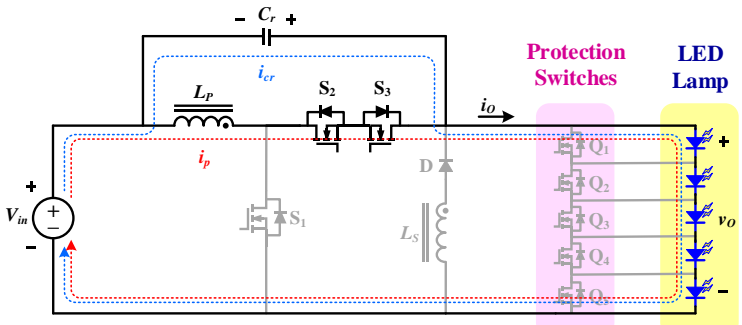

(a) Stage III

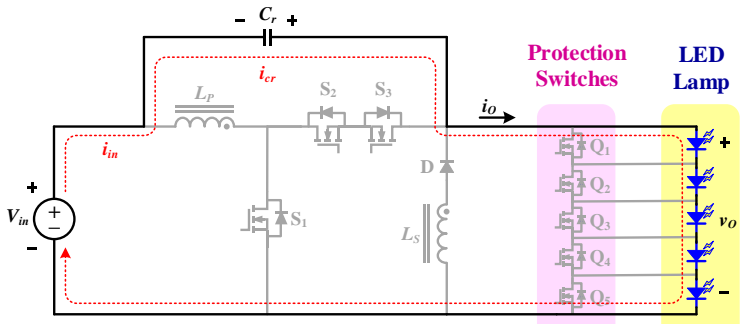

(a) Stage IV

Fig. 5: Operation stages of voltage step-up mode.

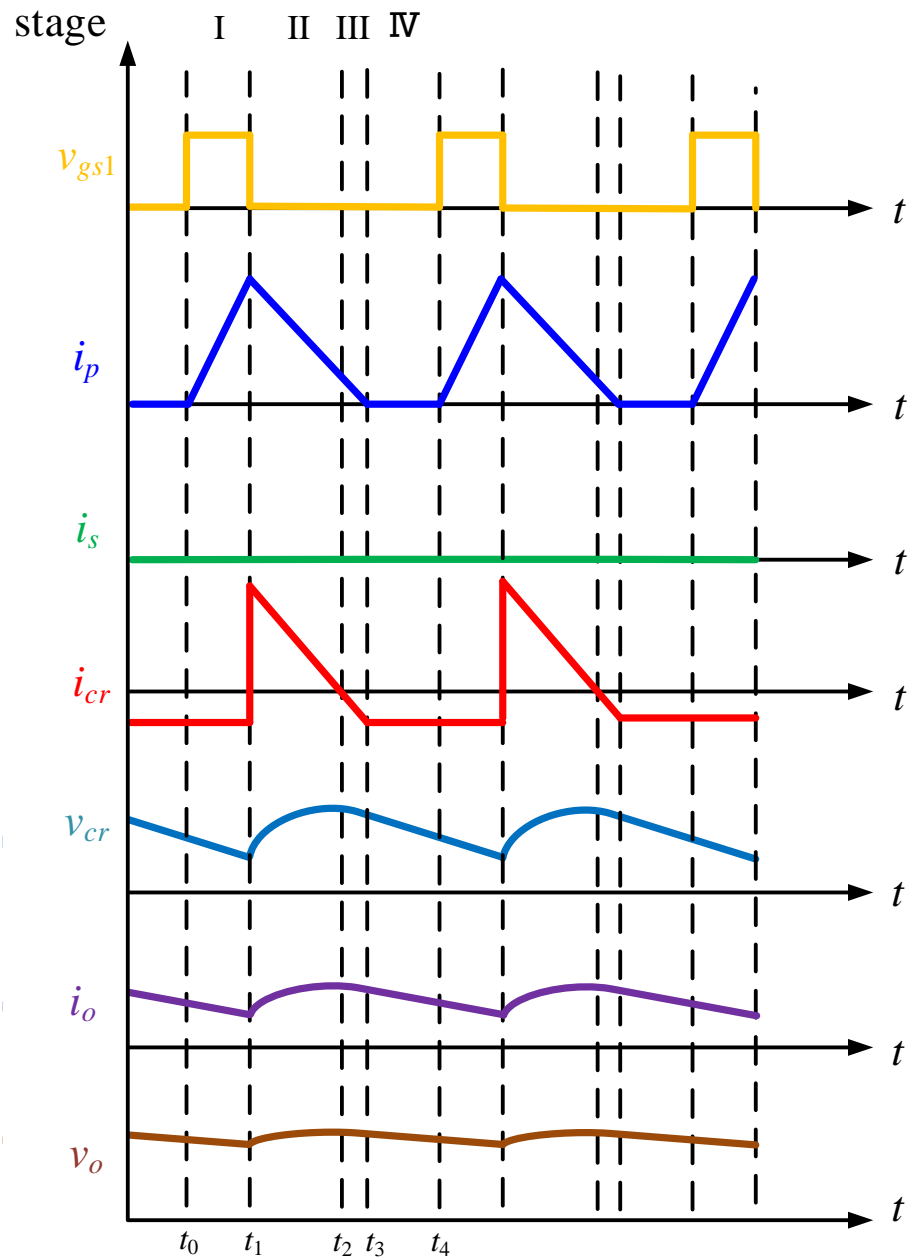

Fig. 6: Theoretical waveforms of step-up mode.

Table 1: Led Lamp Specifications and Driver Circuit Parameters. 


\begin{tabular}{|c|c|}
\hline Battery Voltage, $v_{i n}$ & $8 \mathrm{~V} \sim 13.5 \mathrm{~V}$ \\
\hline Number of LEDs & $1 \sim 5$ \\
\hline LED Lamp Voltage, $V_{\text {LED }}$ & $3.3 \mathrm{~V} \sim 16.5 \mathrm{~V}$ \\
\hline Rated LED Lamp Current, $I_{\text {LED }}$ & $1 \mathrm{~A}$ \\
\hline Maximum LED Lamp Power, $P_{\text {LED }}$ & $16.5 \mathrm{~W}$ \\
\hline Switching Frequency, $f_{S}$ & $100 \mathrm{kHz}$ \\
\hline Primary inductance of Coupled inductor, $L_{p}$ & $4.7 \mu \mathrm{H}$ \\
\hline Secondary inductance of Coupled inductor, $L_{s}$ & $16.8 \mu \mathrm{H}$ \\
\hline Filter Capacitor, $C_{r}$ & $4.7 \mu \mathrm{F}$ \\
\hline
\end{tabular}

Fig. 7 shows the measured waveforms on the key components of the driver circuit for the step-up voltage conversion. In this case, all of the five LEDs are on working and the LED lamp is supplied from the battery set with a terminal voltage of $12 \mathrm{~V}$. The driver steps the voltage from $12 \mathrm{~V}$ to $16.35 \mathrm{~V}$ to have an LED lamp current of $0.85 \mathrm{~A}$.

In the exemplar case of Fig. 8, only two LEDs in the LED lamp are on working, but with three bypassed abnormal LEDs. The driver has to be operated at the voltage step-down conversion mode. In this case, the power conversion circuit outputs an average voltage of $6.32 \mathrm{~V}$ for sustaining the same LED string current of $0.85 \mathrm{~A}$.

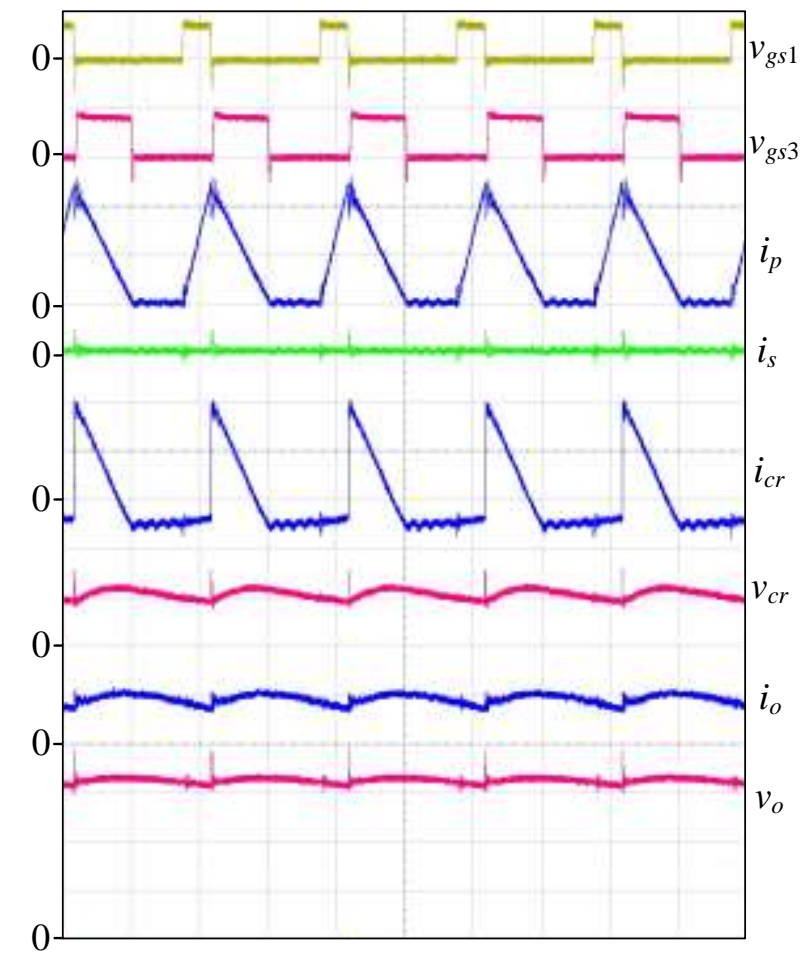

$\left(v_{g s}, v_{g s}: 20 \mathrm{~V} / \mathrm{div} ; v_{c r}, v_{o}: 5 \mathrm{~V} / \mathrm{div} ; i_{p}, i_{s}, i_{c r}: 2 \mathrm{~A} / \mathrm{div} ; i_{o}: 1 \mathrm{~A} / \mathrm{div} ;\right.$ Time:5 $\mu$ s/div)

Fig. 7: Measured voltage and current waveforms on key components for voltage step-down mode.

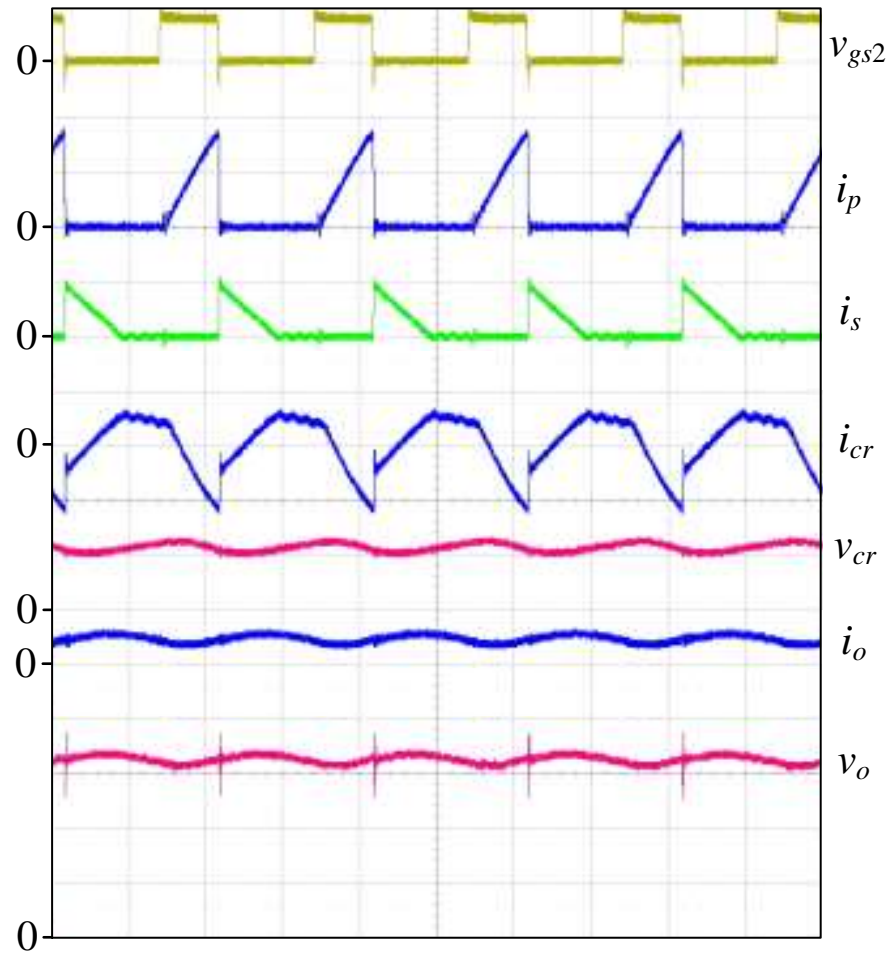

$\left(v_{g s}: 20 \mathrm{~V} / \mathrm{div} ; v_{c r}: 5 \mathrm{~V} / \mathrm{div} ; v_{o}: 2 \mathrm{~V} / \mathrm{div} ; i_{p}, i_{s}, i_{c r}, i_{o}: 2 \mathrm{~A} / \mathrm{div} ;\right.$ Time:5 $\mu \mathrm{s} / \mathrm{div})$

Fig. 8: Measured voltage and current waveforms on key components for voltage step-down mode.

Fig. 9 shows the measured transient waveforms on the key components of the driver circuit when the fault tolerance mechanism is activated for a failure happens to one LED. Before the fault occurs, a battery voltage of $12 \mathrm{~V}$ is originally stepped up to $16.5 \mathrm{~V}$ to drive the LED lamp at the rated current of $1 \mathrm{~A}$ as illustrated in Fig. 9(a). When one LED in the lamp fails at the interval of Fig. 9(b), the damaged LED is short-circuited by activating the associated protection switch. Thereafter, only four LEDs leaves for working in the lamp. At the beginning, the lamp current increases abruptly. With a current feedback control, the duty-ratio is adjusted to be smaller to have a lower voltage of $13.2 \mathrm{~V}$ to obtain the rated lamp current. Eventually, the circuit operation enters to the steady state, as shown in Fig. 9(c).

Fig. 10 shows the transition of the fault tolerance process with three damaged LEDs. For this critical exemplar case, the battery voltage of $12 \mathrm{~V}$ has to be stepped down eventually to $6.6 \mathrm{~V}$ to retain the rated lamp current. Originally, the power conversion circuit is operated with the step-up mode in Fig. 10(a). When a failure happens at the interval of Fig. 10(b), the three damage LEDs are short-circuited by the associated protection switches causing a sudden change on the load of the 
power conversion circuit. At this instant, an abnormally high current is found on the LED current. To reduce this current, the duty-ratio of $S_{1}$ in the voltage step-up converter is adjusted to be smaller and smaller, as shown in Fig. 10(c). At this stage, the circuit operation mode changed from the DCM to the CCM. The duty ratio of $S_{1}$ is gradually reduced to zero. The step-up voltage conversion is swapped to step-down voltage conversion by switching on $S_{2}$ and $S_{3}$ and keeping them at the on state for a short period to ensure $C_{r}$ being completely discharged. Then, the battery supplies the lamp current directly with a zero voltage on $C_{r}$. Fig. 10(e) shows that the circuit operation has been changed to the step-down voltage conversion mode. The filter capacitor $C_{r}$ is then reversely charged. Eventually, the driver circuit enters to the steady-state at the DCM with an LED lamp of 1 A, as shown in Fig. 10(f).

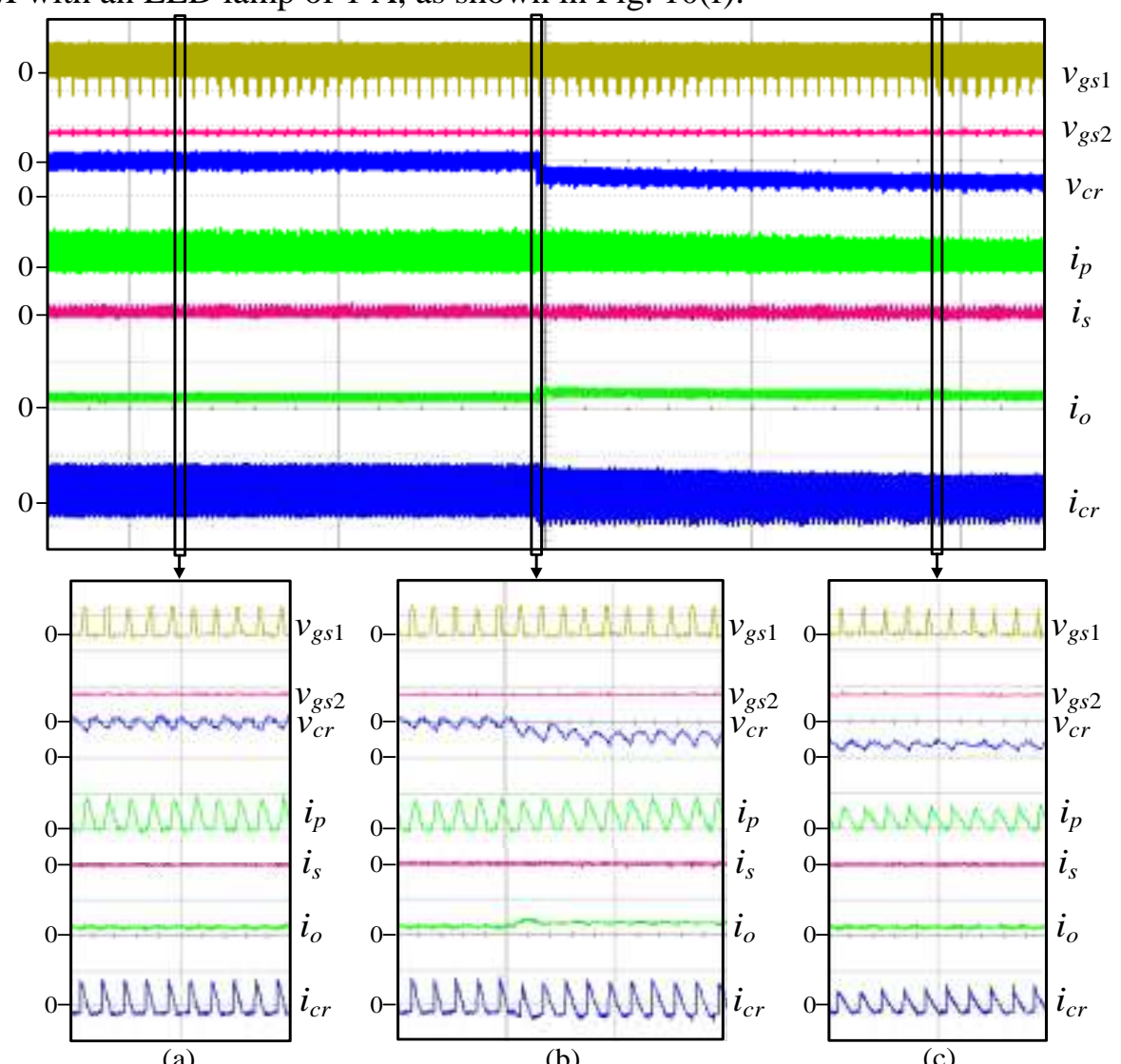

(a)

(b)

(c)

$\left(v_{g s}, v_{g s 2}: 20 \mathrm{~V} / \mathrm{div} ; v_{c r}: 5 \mathrm{~V} / \mathrm{div} ; i_{p}, i_{s}, i_{o}, i_{c r}: 5 \mathrm{~A} / \mathrm{div} ;\right.$ Time:50 $\left.\mu \mathrm{s} / \mathrm{div}\right)$

Fig. 9: Transient voltage and current waveforms when one LED is bypassed. 


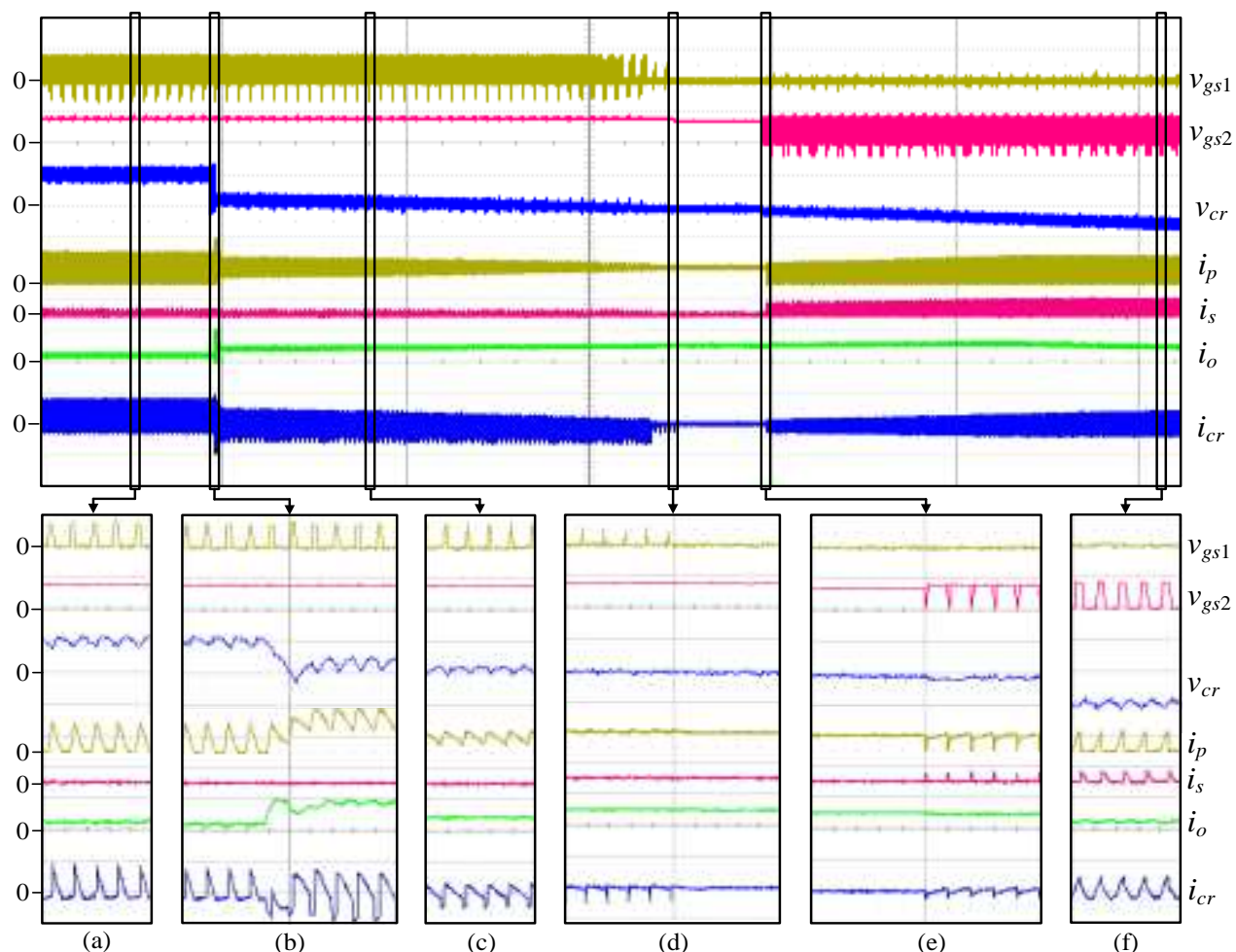

$\left(v_{g s}, v_{g s 2}: 20 \mathrm{~V} / \mathrm{div} ; v_{c r}: 5 \mathrm{~V} / \mathrm{div} ; i_{p}, i_{s}, i_{o}, i_{c r}: 5 \mathrm{~A} / \mathrm{div} ;\right.$ Time:50 $\left.\mu \mathrm{s} / \mathrm{div}\right)$

Fig. 10: Transient voltage and current waveforms from step-up to step-down voltage conversion.

Fig. 11 shows the ripple factors on the LED currents of the proposed driver as compared with the conventionally used dc-to-dc converters at different voltages, currents and powers. With an additional injected current from the coupled inductor, the ripples on the LED currents are always smaller with the proposed driver when the LED lamp is operated with a power higher than $3.3 \mathrm{~W}$.

A comparison on the circuit efficiencies is shown in Fig. 12. For step-up voltage conversion, the efficiency of a boost converter can be higher than that with the proposed driver circuit. However, the boost converter is not applicable for a less number of LEDs at a high battery voltage. The highest efficiency of the proposed LED driver can be as high as $98.2 \%$. On the other hand, the circuit efficiency deteriorates to $78.8 \%$ in the worst case at a very small power with fault tolerance.

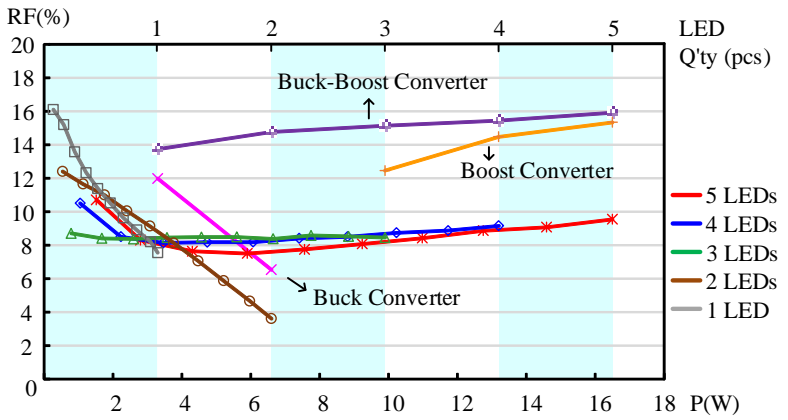

(a) Battery Voltage, $v_{i n}: 8 \mathrm{~V}$

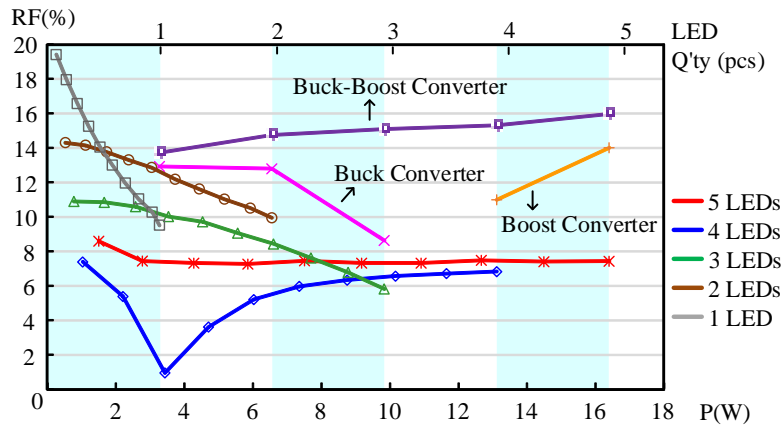

(b) Battery Voltage, $v_{i n}: 12 \mathrm{~V}$ 


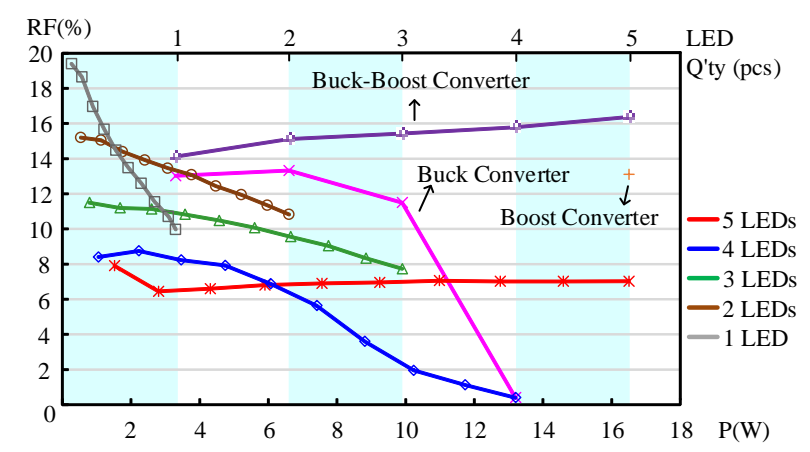

(c) Battery Voltage, $v_{\text {in }}: 13.5 \mathrm{~V}$

Fig. 11: LED current ripple factors at different battery voltages.

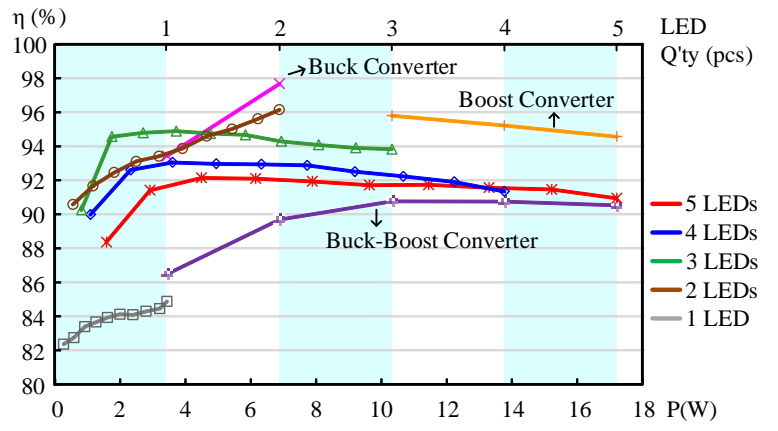

\section{Conclusion}

A high-efficiency dc-to-dc power conversion circuit has been proposed for driving the automotive lamp formed by several LEDs connected in series. With voltage step-down and step-up capabilities, the driver can regulate the LED lamp at the required currents. A laboratory circuit has been designed for an LED lamp rated at $16.5 \mathrm{~W}$ with five LEDs in series. The test results have demonstrated that the LED lamp driver has the capabilities of the voltage step-up and step-down conversions. Experiments have been carried out for emulating the fault occurrence with the one to five LEDs in operation. The fault tolerance function has been verified by activating the protection switches to swap the operation of the driver circuit from step-up voltage conversion into the step-down conversion. A high efficiency of $98.2 \%$ can be achieved at the rated power when the battery voltage is close to the output voltage.

\section{Acknowledgements}

This work was supported by the Ministry of Science and Technology, Taiwan, R. O. C. under Project MOST 1072622-E-150-004 -CC3.

\section{References}

[1] B. Fleming, "Solid State Headlights," IEEE Trans. on Vehicular Technology, vol. 3, no. 3, pp. 12-15, Sep. 2008.

[2] M. S. A. Chowdhury and A. M. Rahman, "Electric efficiency of the lighting technology of auto industry: Recent development and future prospect," in Proc. IEEE ICDRET, pp. 1-5, Jan. 2016.

[3] J. P. Gerber, J. A. Oliver, N. Cordero, T. Harder, J. A. Cobos, M. Hayes, S. C. O’Mathuna, and E. Prem, "Power Electronics Enabling Efficient Energy Usage: Energy Savings Potential and Technological Challenges," IEEE Trans. on Power Electronics, vol. 27, no. 5, pp. 2338-2353, May 2012.

[4] X. Perpiñà, R. J. Werkhoven, M. Vellvehi, J. Jakovenko, X. Jordà, J. M. G. Kunen, P. Bancken, and P. J. Bolt, “Thermal Analysis of LED Lamps for Optimal Driver Integration," IEEE Trans. on Power Electronics, vol. 30, no. 7, pp. 3876- 3891, July 2015.

[5] W. Lin, Q. Zheng, Y. Xu, and Q. Zhang, "Temperature Effect on Performance and Reliability of QR Tapped-Inductor Buck LED Driver," in Proc. IEEE PEAC, pp. 1397-1400, Nov. 2014.

[6] H. Akca, Y. Yasa, R. Ayaz, A. Durusu, A. Ajder, I. Nakir, and M. Tanrioven, "Thermal Management of Power LED System," in Proc. IEEE ICRERA, pp. 760-764, Oct. 2014.

[7] Z. Zha, H. Wong, and Y. Han, "An LED Driver with Thermal Control Function," in Proc. IEEE ICSICT, pp. 1-3, Oct. 2014. 
[8] S. N. Lin, T. Y. Lee. Z. Y. He, Y. C. Hsieh, Y. N. Chang, and C. S. Moo, "An LED Driver with Wide Operation Range for Automotive Lighting," in Proc. IEEE ICIT, pp. 384-387, Feb. 2019.

[9] D. Guilbert, A. Gaillard, A. N'Diaye, and A. Djerdir, "Energy Efficiency and Fault Tolerance Comparison of DC/DC Converters Topologies for Fuel Cell Electric Vehicles," in Proc. IEEE ITEC, pp. 1-7, June 2013.

[10] Nirmal, P. K. Jain, and A. Kumar, "Interleaved DC to DC Buck Converter for Low Power Application," in Proc. IEEE ICEPE, pp. 1-5, June 2015.

[11] C. H. Hsieh, T. J. Liang, L. S. Yang, R. L. Lin, and K. H. Chen, "Analysis and Implementation of a DC-DC StepDown Converter for Low Output-Voltage and High Output-Current Applications," in Proc. IEEE ISCAS, pp. 36973700, May 2010.

[12] F. marvi, E. Adib, and H. Farzanehfard, "Interleaved Zero Voltage Switching Coupled Inductor Buck Converter for Low Voltage-High Current Applications," in Proc. IEEE PEDSTC, pp. 236-241, Feb. 2013.

[13] K. Bendaoud, J. Laassiri, S. D. Krit, and L. Maimouni, "Design and Simulation DC-DC Power Converters Buck and Boost for Mobile Applications Using Matlab/Simulink," in Proc. IEEE ICEMIS, pp. 1-6, Sep. 2016.

[14] A. Nahavandi, M. T. Hagh, M. B. B. Sharifian, and S. Danyali, "A Nonisolated Multiinput Multioutput DC-DC Boost Converter for Electric Vehicle Applications," IEEE Trans. on Power Electronics, vol. 30, no. 4, pp. 1818-1835, May 2014.

[15] M. K. Yang and W. Y. Choi, "Design of High-Efficiency Power Conversion System for Low-Voltage Electric Vehicle Battery Charging," in Proc. IEEE ICIT, pp. 289-294, Mar. 2014.

[16] C. H. Chang, E. C. Chang, C. A. Cheng, and C. L. Shen, "A Step-Up/Down Inverter Implemented with the Boost interleaved Buck-Boost DC-DC Converter," in Proc. IEEE IFEEC, pp. 1-6. Nov. 2015.

[17] M. Arias, D. G. Lamar, J. Sebastian, D. Balocco, and A. A. Diallo, "High-Efficiency LED Driver without Electrolytic Capacitor for Street Lighting," IEEE Trans. on Industry Applications, vol. 49, no. 1, pp. 127-137, Jan./Feb. 2013.

[18] H. Dong, X. Xie, H. Chen, and Z. Jin, "A High Power Factor LED Driver Based on Improved Forward-Flyback without Electrolytic Capacitor," in Proc. IEEE APEC, pp. 2404-2411, Mar. 2017.

[19] L. Wang, B. Zhang, D. Qiu, and L. Wang, "A Novel Flicker-Free AC-DC LED Driver without Electrolytic Capacitor," in Proc. IEEE ICIT, pp. 370-375, Mar. 2017.

[20] Y. Zhang and K. Jin, "A Single-Stage Electrolytic Capacitor-Less AC/DC LED Driver," in Proc. IEEE PEAC, pp. 881-886, Nov. 2014. 